\title{
Effect of expert-patient teaching on empathy in nursing students: a randomized controlled trial
}

This article was published in the following Dove Press journal:

Psychology Research and Behavior Management

\author{
Paola Ferri (D) ${ }^{\prime}$ \\ Sergio Rovesti ${ }^{\prime}$ \\ Maria Stella Padula' \\ Roberto D'Amico \\ Rosaria Di Lorenzo ${ }^{3}$ \\ 'Department of Biomedical, Metabolic, \\ and Neural Sciences, University of \\ Modena and Reggio Emilia, Modena \\ 4II25, Italy; ${ }^{2}$ Research and Innovation \\ Area, Department of Maternal-Infant and \\ Adult Medical and Surgical Sciences, \\ University of Modena and Reggio Emilia, \\ Modena 4I I 24, Italy; ${ }^{3}$ Psychiatric \\ Intensive Treatment Facility, Department \\ of Mental Health and Drug Abuse, AUSL \\ Modena, Modena 4I I22, Italy
}

Background: Empathy is a relevant clinical competence for nursing students. Involvement of expert patients in nursing education could help students develop their innate capacity to empathize.

Objective: To evaluate the effect of expert-patient teaching on empathy development in nursing students.

Methods: This randomized controlled trial was conducted among 144 first-year undergraduate nursing students divided into two equal groups. In the experimental group, the educational intervention consisted of a seminar focused on empathy, followed by a presentation on expert-patient function. Subsequently, each student participated in two interactive meetings with nursing teacher and expert patient. At the end, the nursing teacher encouraged students to reflect on this experience. In the control group, students only attended a similar seminar focused on empathy and afterward participated in two interactive meetings with a nursing teacher to reflect on this topic without expert-patient involvement. Before (T0) and after (T1) the training intervention, the Balanced Emotional Empathy Scale, Jefferson Scale of Empathy - Health Professions Student (JSE-HPS), and a short demographic questionnaire were administered to the two student groups to measure their empathy levels. The study was approved by the Local Ethics Committee of Area Vasta Emilia Nord (protocol 1763, May 11, 2017). Data were statistically analyzed.

Results: We found a statistically significant difference between mean scores at T0 and $\mathrm{T} 1$ in both scales in the experimental group. Male students, who presented significantly lower levels of empathy at baseline in comparison with females, showed increased in empathy after training on the the Balanced Emotional Empathy Scale in both the experimental and control groups.

Conclusion: The present study highlights that involvement of expert patients in teaching is effective in improving empathy levels in both male and female nursing students. Expertpatient teaching can be a promising nursing-education modality for developing empathy.

Keywords: empathy, nursing education, students, expert patient

\section{Introduction}

Empathy is a complex concept in which the different dimensions (emotional, moral, cognitive, and behavioral) work together. Empathy competence includes identification with the patient's suffering, the internal motivation to empathize, understanding of the patient's perspective, and the ability to convey understanding of these emotions and perspectives back to the patient. ${ }^{1,2}$ Patients may not be able to describe the concept of empathy, but they are able to determine whether they have been treated with empathy. ${ }^{3}$ There is a good correlation between empathy and health-care outcomes: patient satisfaction, therapeutic adherence, and low occurrence of errors and complications. ${ }^{4-8}$ The
Correspondence: Paola Ferri Department of Biomedical, Metabolic and Neural Sciences, University of

Modena and Reggio Emilia via Campi 287, Modena 4I I 25, Italy

Tel +390592055456

Fax +390592055483

Email paola.ferri@unimore.it 
literature shows that poor empathy exposes nurses to higher levels of emotional exhaustion and job dissatisfaction, as well as an increase in health-care conflicts. ${ }^{9,10}$ In nursing care, empathic skills are required for understanding the emotions and experiences of patients, ${ }^{11}$ and nurses can improve patients' conditions through their "relational ability". ${ }^{12}$ Despite the fact that empathic skills are essential for effective nursing care, studies have suggested that nurses have low or intermediate empathic skills and patients suffer from this lack of empathic aptitude. ${ }^{13-15}$ According to many authors, ${ }^{10,16-21}$ nursing students show similarly low levels of empathy, which can decrease as their course of studies progresses. Most authors have highlighted that for the development of nursing students, empathic skills are necessary in patient care. ${ }^{12,14}$ As such, it is essential to find effective ways to empower nursing students with empathic skills. ${ }^{22,23}$

Over the last decade, scientific research on empathy has broadened our knowledge of its neural architecture, delineating that it consists of a dynamic, malleable, and potentially controllable phenomenon. ${ }^{24}$ Innate empathic skills can be improved through educational training and experience; acquisition of empathy skills requires experiential and reflective strategies. , $^{2,22,25-27}$ Through educational interventions, like involvement of patients and relatives and the use of illness narratives, students can be helped to get in touch with their innate capacities of empathy and experientially learn the value of this kind of understanding in nursing practice. ${ }^{28,29}$ In accordance with a recent review, simulation-based interventions allow students to "put themselves in patients' shoes" and help them to feel perspectives, experiences, and needs of others. ${ }^{30}$ Students, patients, teachers, and health professionals have identified many benefits in including patient trainers in education courses, ${ }^{31}$ such as increased self-esteem, new insights into solving problems for patients, awareness of patients' perspectives, and an increase in communication skills for students. ${ }^{32-34}$ A systematic review concluded that there have been few studies on the benefits of service-user involvement in undergraduate nursing education. ${ }^{35}$ More recently, Feijoo-Cid et al reported nursing-student satisfaction with expert-patient illness narratives in providing a new humanized perspective of care. ${ }^{36}$ An online education course in which recorded patient interviews were embedded as learning materials reported a significant improvement in empathic skills among nursing students. ${ }^{37}$

At present, patient involvement in health-education practice is not well established, and its educational impact on student empathy has not been completely evaluated. ${ }^{38,39}$ In accordance with most authors, well-designed trials with appropriate control groups and validated tools are necessary for implementing effective educational strategies to increase empathy. ${ }^{3,26,40}$ The objective of this study was to evaluate the effect of expert-patient teaching on the development of empathy in nursing students.

\section{Methods \\ Study design}

This was a monocentric randomized controlled study exploring levels of empathy before and after an educational intervention in two groups of 72 students each: an experimental group (EG) and a control group (CG). In the $\mathrm{EG}$, the educational intervention was focused on the function of the expert patient in training nursing students who had previously participated in a seminar focused on empathy. In the $\mathrm{CG}$, students attended a similar seminar addressing empathy, and afterward participated in two interactive meetings with a nursing teacher to reflect on this topic.

\section{Setting and period}

This research was conducted in the University Nursing Course in Modena (Italy) from April 1 to September 30, 2017 during the second semester of the academic year.

\section{Participants}

All students enrolled in the first year of the nursing course were eligible to participate $(n=157)$ and were recruited according to our inclusion criteria (age $\geq 18$ years, informed consent for study participation) and exclusion criteria (irregularity in payment of university fees, dropped out of nursing school). According to our criteria, participants comprised 144 students (Figure 1).

\section{Recruitment}

Students were enrolled during an informational meeting focused on the study purpose, procedures, and characteristics. During the meeting, the investigator answered all participants' questions and gave them a written information sheet. After 1 week, the experimenter asked the student participants for their informed consent. Anonymity regarding pre- and posttest results was guaranteed by an identification code. Student participation was voluntary and could be terminated at any time, without any negative impact on their university course. 


\section{Randomization and grouping of participants}

The randomization list, stratified by sex, was generated by Stata software to assign participants randomly to the EG and $C G$ at a ratio of $1: 1$. Stratification by sex was considered necessary, due to the significant differences in the level of empathy described in the literature. ${ }^{41,42}$ Randomization was performed by an independent statistician from the Medical Statistics Unit of the University of Modena and Reggio Emilia, who was not involved in data collection or analysis. The statistician associated the list of participant codes in the randomization list. Study experimenters were not involved in generation of the randomization list or allocation concealment. Student recruitment was completed before randomization. After randomization, the 144 students enrolled were equally divided into two groups: the EG $(n=72)$ and the $C G(n=72)$. In each group, females and males were similarly distributed: 59 females and 13 males. While participants were aware of the group they had been assigned to, outcome assessors and data analysts were kept blinded to the allocation.

\section{Educational interventions}

The educational interventions, which were completed in a single day, differed in the two groups. In the EG, the educational intervention started with a theoretical seminar on the topic of empathy in the construction of a therapeutic relationship, conducted by a psychology professor (1.5 hrs). Afterward, another teacher presented a theoretical seminar (1.5 hrs), the function of the expert patient as trainer, enhancing the complementary nature of the experiential knowledge of patients and caregivers with the theoretical knowledge of nurses. In accordance with the literature, we selected as "expert patient" a person who had experienced a health problem now resolved or had had a chronic health problem but was not in an acute phase of illness and not admitted to a health facility. The expert patient is thus a volunteer who wishes to share his/her experiential knowledge of illness and nursing care. In order to become a trainer, the expert patient has to present some essential characteristics: good awareness of one's own health problem, no feelings of retaliation toward nurses, motivation to teach student nurses, and good communication and interpersonal skills with the ability to reflect. Subsequently, each EG student participated in two interactive meetings with a nursing teacher and an expert patient $(2+2$ hours). Two expert patients (a 70year-old woman with amyloidosis and a 40-year-old woman with previous breast cancer) shared their illness stories, including good and bad experiences of nursing care, with the students, in a single contact, in accordance with the "spectrum of involvement" of Towle et al. ${ }^{31}$ Moreover, the expert patients gave students the opportunity to ask questions. The interactive meetings were held in small groups, and were aimed at developing empathic skills. In these educational activities, the patient trainer made the students more sensitive to illness experience, helping them to reflect on the impact of nursing care on patient and/or caregiver well-being. In particular, the patient trainer sharing his/her illness experience with students permitted them to appreciate a subjective approach to illness conditions. At the end, the nursing teacher conducted a debriefing intervention to reflect on this educational experience (1 hour).

In the $\mathrm{CG}$, the educational intervention also started with a theoretical seminar on the topic of empathy in the construction of a therapeutic relationship, discussed by a psychology professor (1.5 hours). Subsequently, each CG student participated in two interactive meetings with a nursing teacher $(2+2$ hours $)$. The interactive meetings were held in small groups with interactive modality, and were aimed at developing empathic skills. Participants could review their clinical experiences, rethinking and reflecting on the stories they had gathered from patients. At the end, a nursing teacher conducted a debriefing intervention to reflect on this educational experience (1 hour).

\section{Instruments}

Before (T0) and after (T1) the training intervention, the Balanced Emotional Empathy Scale (BEES) and Jefferson Scale of Empathy - Health Profession Student (JSEHPS) were administered to the students in the two groups to measure their empathy levels. A short demographic questionnaire was administered as well.

\section{Balanced Emotional Empathy Scale}

The 30-item BEES is a reliable and valid instrument aimed at detecting the level of emotional empathy in terms of propensity to be involved in the emotions of others and tendency to develop positive interpersonal relationships. ${ }^{43}$ BEES questions ask participants to indicate their level of agreement or disagreement with each statement: from 1 (strongly disagree) to 7 (strongly agree) in the Italian BEES version. ${ }^{42}$ Items are equally positively and negatively oriented, in order to discourage acquiescent or socially desirable responses. Higher scores represent 


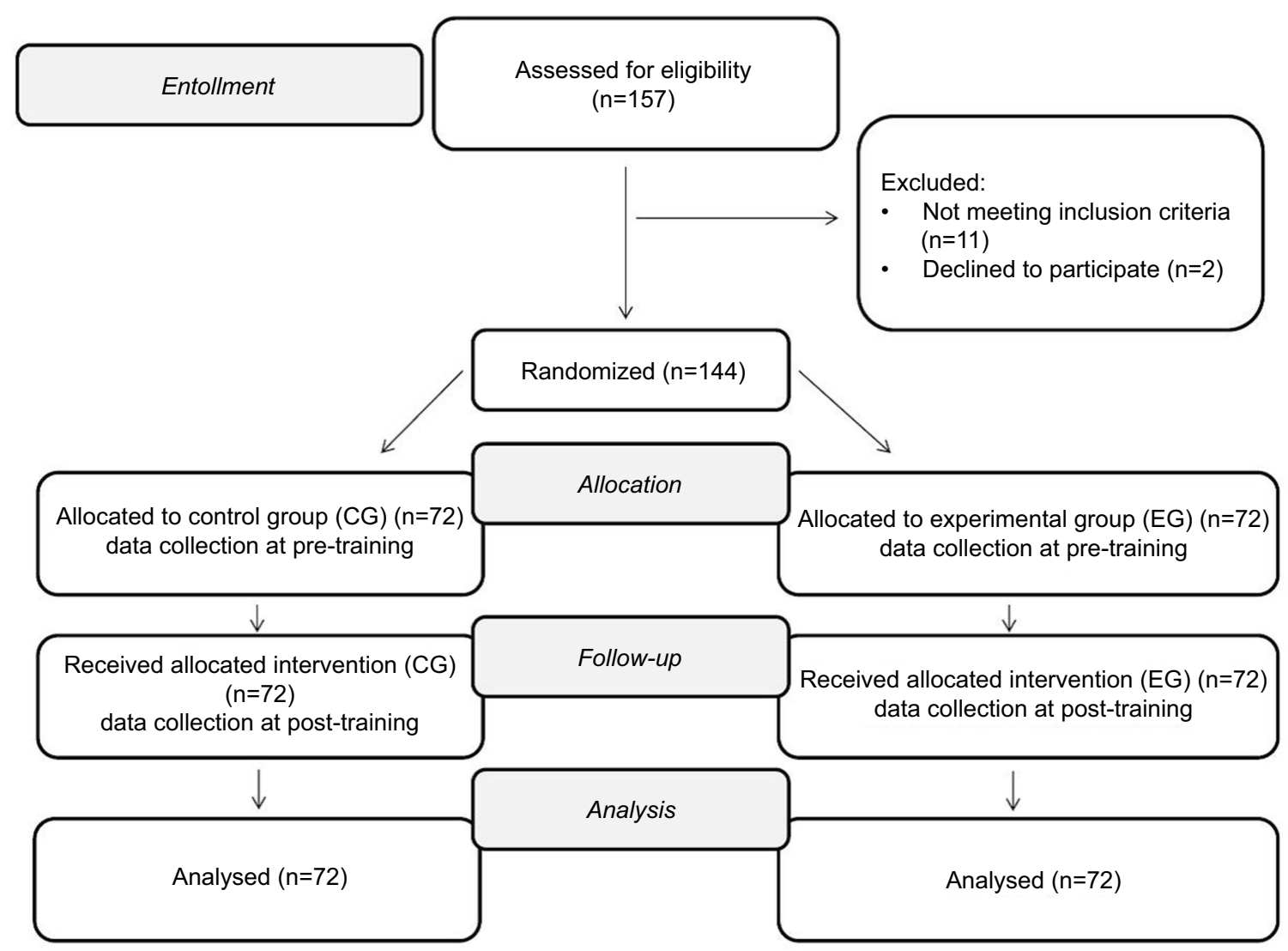

Figure I Study design and sample size.

higher levels of emotional empathy. Cronbach's $\alpha$ ranged from 0.83 to 0.87 in previous samples of nursing students and nurses, ${ }^{42}$ and in the present study Cronbach's $\alpha$ was 0.91 .

\section{Jefferson Scale of Empathy - Health Profession Student}

The 20-item JSE-HPS is a reliable and valid self-questionnaire composed of three self-reported subscales - perspective taking, compassionate care, and standing in the patient's shoes - aimed at subjectively measuring the level of general empathy. ${ }^{25}$ JSE-HPS questions ask participants to indicate their level of agreement or disagreement with each statement (from 1 [strongly disagree] to 7 [strongly agree]), with ten items negatively worded (reverse-coded when scored). The total score ranges from a minimum of 20 to a maximum of 140: higher scores denote higher levels of empathy. Cronbach's $\alpha$ has ranged $0.80-0.89$ in previous samples of medical students, physicians, and nurses. ${ }^{25}$ Psychometric qualities of the JSE-HPS were confirmed in an Italian sample of nursing students. ${ }^{44}$ In the present study, Cronbach's $\alpha$ was 0.85 . A short demographic questionnaire was administered to assess age and sex in the sample.

\section{Sample size}

In a pilot study with an identical primary outcome and conducted in a similar training setting, ${ }^{41}$ the mean level of emotional empathy detected with the BEES at T0 was 30.19 (SD 17.2) in the EG and 31.56 (SD 20.4) in the CG. Assuming a minimum difference between the two groups of 7 on the mean total value of the BEES, SD 17, $\alpha=0.05$, and a power of at least 0.8 , the minimum sample to be enlisted in the present study was 72 students for each group by $\mathrm{G}$ power. ${ }^{45}$

\section{Data analysis}

Data were analyzed by a statistician from the Medical Statistics Unit of the University of Modena and Reggio Emilia using Stata 14 (StataCorp, College Station, TX, USA). Statistical analysis was conducted by a researcher who did not know which group the data belonged to. Frequencies, percentages, averages, and SDwere used to summarize the characteristics of participants and scores on 
the BEES and JSPE-HPS. For statistical comparisons between the mean scores of the two scales (at T0 and T1 in the EG and CG), Student's paired $t$-test was applied. For comparison of categorical variables between groups, $\chi^{2}$ or Fisher's tests were used when appropriate. Statistical significance was defined as $P<0.05$. All data were analyzed according to the intention-to-treat principle.

\section{Ethical considerations}

The present study was approved by the local ethics committee of Area Vasta Emilia Nord (protocol 1763 of May 11, 2017) and conducted following the principles of the World Medical Association Declaration of Helsinki (1964). All students were informed that their participation in the study was voluntary and they were free to withdraw at any time without affecting their academic course. Written consent of all participants was obtained. All students were further assured that their information would be kept confidential. The researchers took care to ensure that students did not feel pressured while responding.
All expert patients voluntarily participated in this research without funding and gave us written informed consent. At the end of this study, the researchers made the experimental education training available to the $\mathrm{CG}$, in order to give the same opportunity to all students.

\section{Results}

\section{Characteristics of participants}

All 144 nursing students completed the study. The majority of participants were female ( $88 \%$ in each group) and were 20.9 (SD 2.6) and 20.7 (SD 2.6) years old on average in the EG and CG, respectively (Table 1). There were no significant differences in demographic variables (age and sex) between the two groups.

\section{Balanced Emotional Empathy Scale}

At pretraining (T0), the BEES mean score was 31.03 (SD 17.62) in the EG and 29.33 (SD 15.64) in the CG, without any statistically significant difference between them (Table 2). At

Table I Baseline demographic characteristics for each group

\begin{tabular}{|c|c|c|c|}
\hline & $\begin{array}{l}\text { Experimental group } \\
(E G) \\
(n=72)\end{array}$ & $\begin{array}{l}\text { Control group } \\
(C G) \\
(n=72)\end{array}$ & $\begin{array}{l}\text { EG vs CG } \\
\text { Statistical test } \\
p \text { value }\end{array}$ \\
\hline \multicolumn{4}{|c|}{ Gender, n (\%) } \\
\hline $\begin{array}{l}\text { Female } \\
\text { Male }\end{array}$ & $\begin{array}{l}59(88 \%) \\
13(12 \%)\end{array}$ & $\begin{array}{l}59(88 \%) \\
13(12 \%)\end{array}$ & $\begin{array}{l}\chi^{2}=0.00 \\
p=N S^{*}\end{array}$ \\
\hline \multicolumn{4}{|c|}{ Age, mean \pm SD } \\
\hline Years & $20.9 \pm 2.6$ & $20.7 \pm 2.6$ & $\begin{array}{l}t=0.39 \\
p=N S^{*}\end{array}$ \\
\hline
\end{tabular}

Abbreviations: EG, Experimental group; CG, Control group; *NS = Not Significant.

Table 2 BEES mean scores in the EG and CG, at T0 and TI

\begin{tabular}{|c|c|c|c|}
\hline & $\begin{array}{l}\text { Experimental group } \\
\text { (EG) } \\
(n=72)\end{array}$ & $\begin{array}{l}\text { Control group } \\
\text { (CG) } \\
(n=72)\end{array}$ & $\begin{array}{l}\text { EG vs CG } \\
\text { Statistical test } \\
\text { (unpaired } t \text {-test) } \\
P \text { value }\end{array}$ \\
\hline \multicolumn{4}{|c|}{ BEES, mean \pm SD } \\
\hline $\begin{array}{l}\text { Pre-training } \\
\text { (T0) }\end{array}$ & $31.03 \pm 17.62$ & $29.33 \pm 15.64$ & $\begin{array}{l}t=0.61 \\
p=0.54\end{array}$ \\
\hline $\begin{array}{l}\text { Post-training } \\
\text { (TI) } \\
\text { T0 vs TI } \\
\text { Statistical test } \\
\text { (paired t-test) } \\
\text { p value }\end{array}$ & $\begin{array}{l}38.19 \pm 16.98 \\
t=2.81 \\
p=0.006\end{array}$ & $\begin{array}{l}31.0 \pm 15.90 \\
t=0.68 \\
p=0.50\end{array}$ & $\begin{array}{l}t=2.47 \\
\boldsymbol{p}=\mathbf{0 . 0 2}\end{array}$ \\
\hline
\end{tabular}

Abbreviations: BEES, Balanced Emotional Empathy Scale; EG, Experimental group; CG, Control group; T0, Before training intervention; TI, After training intervention. 


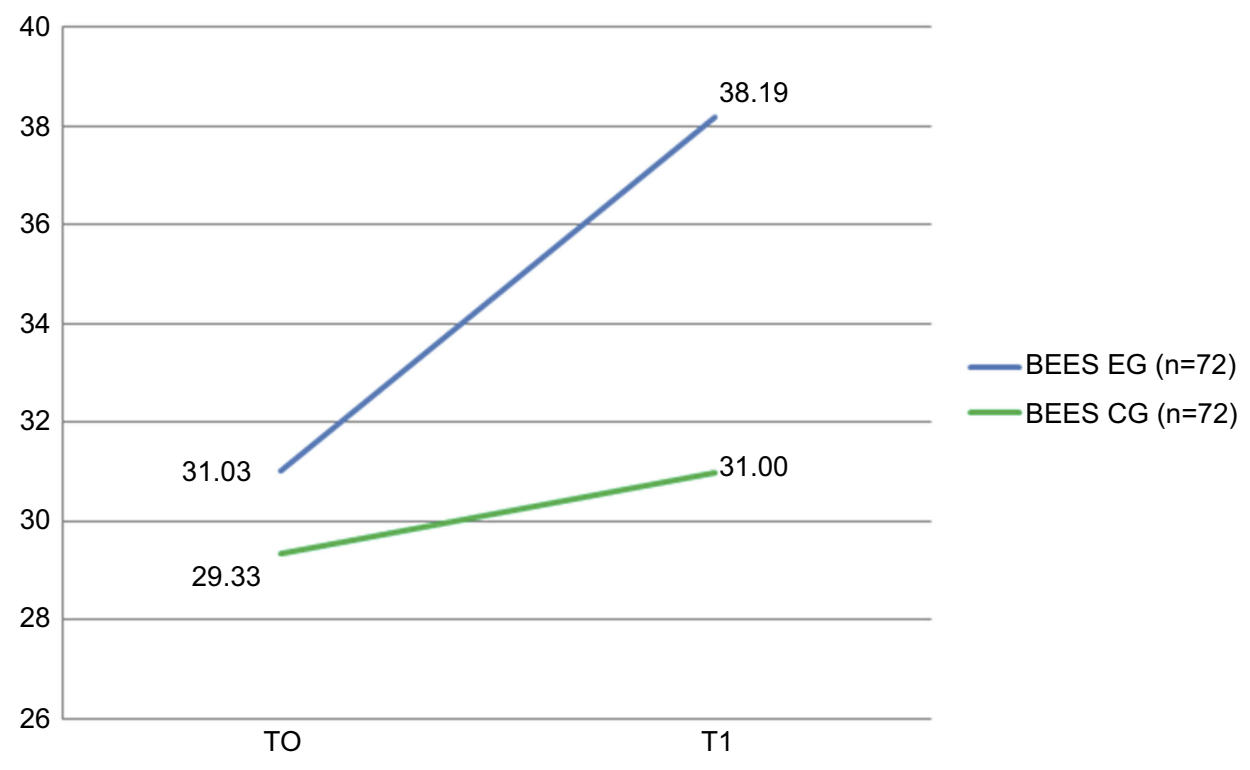

Figure 2 Balanced Emotional Empathy Scale mean scores in the experimental and control groups at T0 and TI.

Abbreviations: BEES EG, Balanced Emotional Empathy Scale Experimental group; BEES CG, Balanced Emotional Empathy Scale Control group; T0, Before training intervention; TI, After training intervention.

posttraining (T1), the mean score increased in both groups (Figure 2). We found a statistically significant difference between mean scores at $\mathrm{T} 0$ and $\mathrm{T} 1$ (31.03 vs 38.19 , $P=0.006)$ in the EG only.

\section{Jefferson Scale of Empathy - Health Profession Student}

At T0, the JSE-HPS mean score was 115.92 (SD 10.10) in the EG and 112.58 (SD 11.51) in the CG, without any statistically significant difference (Table 3). At $\mathrm{T} 1$, the mean score increased in both groups (Figure 3). We found a statistically significant difference between mean scores at T0 and T1 (115.92 vs $121.76, P=0.0006)$ in the EG only.

At $\mathrm{T} 0$, there were no significant differences in the three subscales of JSE-HPS scores between the two groups (Table 4). At $\mathrm{T} 1$, the subscales perspective-taking and compassionate care were statistically significantly higher in the EG than the CG.

\section{Sex differences}

At T0, mean BEES scores of females and males did not statistically significantly differ in either group (Figure 4).

Table 3 JSE-HPS mean scores in the EG and CG, at TO and TI

\begin{tabular}{|c|c|c|c|}
\hline & $\begin{array}{l}\text { Experimental group } \\
(E G) \\
(n=72)\end{array}$ & $\begin{array}{l}\text { Control group } \\
(C G) \\
(n=72)\end{array}$ & $\begin{array}{l}\text { EG vs CG } \\
\text { Statistical test } \\
\text { (unpaired } t \text {-test) } \\
\text { p value }\end{array}$ \\
\hline \multicolumn{4}{|c|}{ JSE-HPS, mean \pm SD } \\
\hline $\begin{array}{l}\text { Pre-training } \\
\text { (T0) } \\
\text { Post-training } \\
\text { (TI) } \\
\text { T0 vs TI } \\
\text { Statistical test } \\
\text { (paired } t \text {-test) } \\
\text { p value }\end{array}$ & $\begin{array}{l}115.92 \pm 10.10 \\
121.76 \pm 9.95 \\
t=-3.50 \\
p=0.0006\end{array}$ & $\begin{array}{l}|| 2.58 \pm|| .5 \mid \\
|| 4.17 \pm \mid 2.27 \\
t=-0.80 \\
p=0.43\end{array}$ & $\begin{array}{l}t=1.84 \\
p=0.06 \\
t=4.08 \\
\mathbf{p}=\mathbf{0 . 0 0 0 1}\end{array}$ \\
\hline
\end{tabular}

Abbreviations: JSE-HPS, Jefferson Scale of Empathy-Health Professions Student; EG, Experimental group; CG, Control group; T0, Before training intervention; TI, After training intervention. 


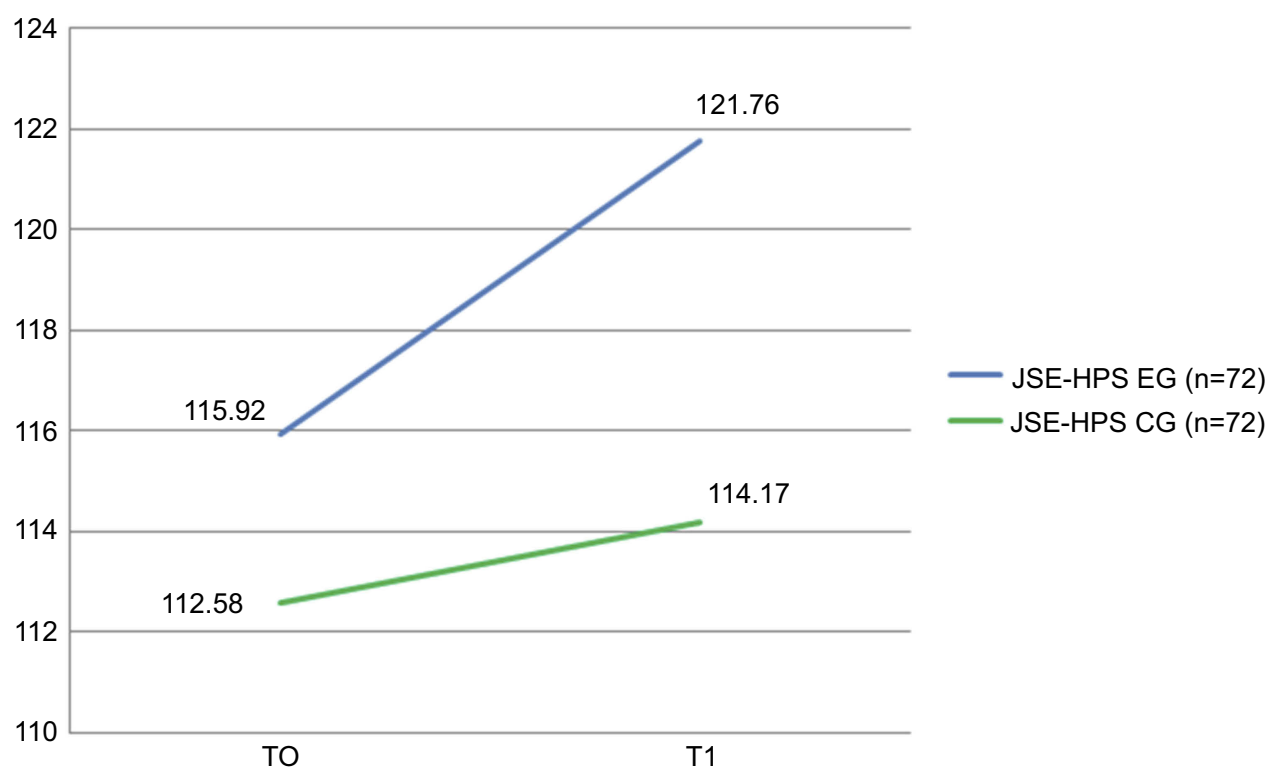

Figure 3 Jefferson Scale of Empathy - Health Profession Student mean scores in the experimental and control groups at T0 and TI.

Abbreviations: JSE-HPS EG, Jefferson Scale of Empathy-Health Professions Student Experimental group; JSE-HPS CG, Jefferson Scale of Empathy-Health Professions Student Control group; TO, Before training intervention; TI, After training intervention.

Table 4 Mean scores of JSE-HPS subscales in the EG and CG, at TO and TI

\begin{tabular}{|c|c|c|c|}
\hline & $\begin{array}{l}\text { Experimental group (EG) } \\
(n=72)\end{array}$ & $\begin{array}{l}\text { Control group } \\
(C G) \\
(n=72)\end{array}$ & $\begin{array}{l}\text { Statistical test } \\
\text { (unpaired } t \text {-test) } \\
p \text { value }\end{array}$ \\
\hline \multicolumn{4}{|c|}{ Pre-training (T0) subscales of JSE-HPS, mean \pm SD } \\
\hline Perspective taking & $60.42 \pm 6.55$ & $58.31 \pm 7.16$ & $\begin{array}{l}t=1.84 \\
p=0.07\end{array}$ \\
\hline Compassionate care & $46.71 \pm 4.27$ & $45.49 \pm 4.60$ & $\begin{array}{l}t=1.65 \\
p=0.10\end{array}$ \\
\hline Standing in the patient's shoes & $8.79 \pm 2.32$ & $8.79 \pm 2.64$ & $\begin{array}{l}t=0.00 \\
p=1\end{array}$ \\
\hline \multicolumn{4}{|c|}{ Post-training (TI) subscales of JSE-HPS, mean \pm SD } \\
\hline Perspective taking & $64.17 \pm 5.40$ & & $\begin{array}{l}t=4.02 \\
p=0.0001\end{array}$ \\
\hline Compassionate care & $48.69 \pm 4.78$ & $45.33 \pm 6.01$ & $\begin{array}{l}t=3.71 \\
p=0.0003\end{array}$ \\
\hline Standing in the patient's shoes & $8.90 \pm 2.50$ & $9.04 \pm 2.41$ & $\begin{array}{l}t=0.33 \\
p=0.73\end{array}$ \\
\hline
\end{tabular}

Abbreviations: JSE-HPS, Jefferson Scale of Empathy-Health Professions Student; EG, Experimental group; CG, Control group; T0, Before training intervention; TI, After training intervention.

At $\mathrm{T} 1$ in the EG, mean BEES scores of both females and males had statistically significantly increased in comparison with T0 (females, $t=2.077, P=0.04$; males, $t=2.20$, $P=0.04)$. At $\mathrm{T} 1$ in the $\mathrm{CG}$, mean BEES scores of males had statistically significantly increased in comparison with T0 ( $t=2.82, P=0.02)$, whereas mean BEES scores of females did not statistically significantly differ in comparison with T0 $(t=0.09, P=0.92)$. 


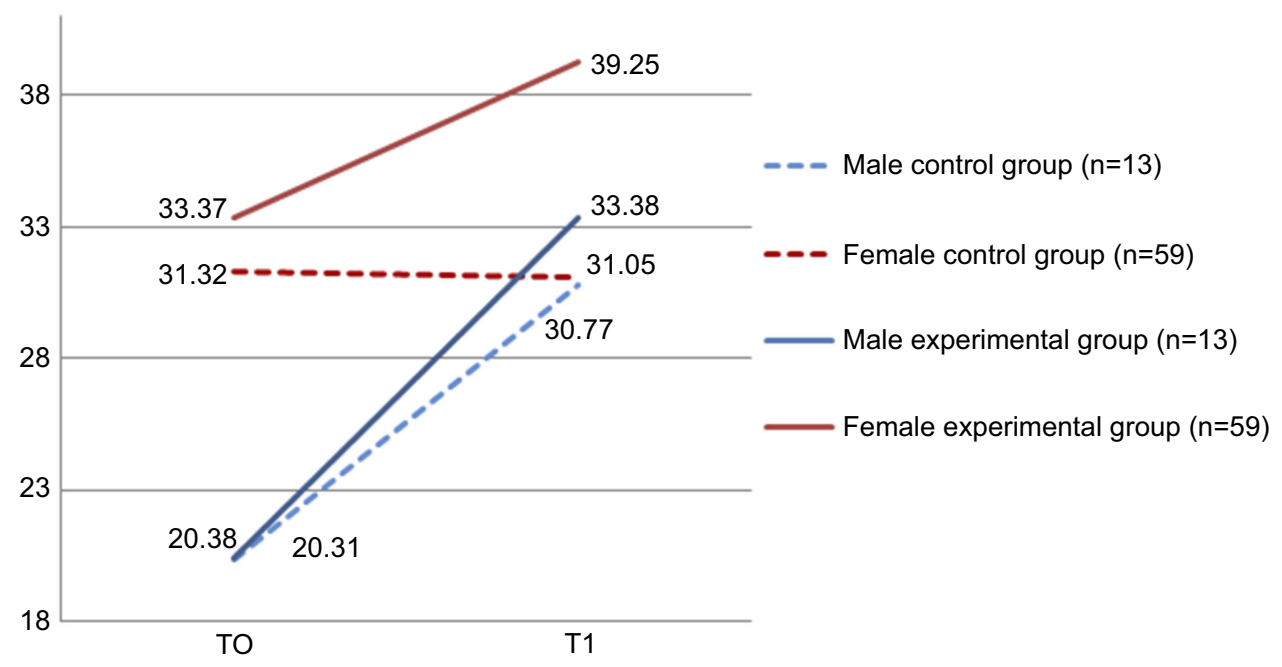

Figure 4 Mean Balanced Emotional Empathy Scale scores in the experimental and control groups, divided by sex.

Abbreviations: T0, Before training intervention; TI, After training intervention.

\section{Discussion}

The results of the present study showed that the involvement of expert patients in educational activities increased empathy scores in the EG on both scales (BEES and JSEHPS). This result indicates that the skill training was effective in improving the empathic ability of students, suggesting that comprehension and sharing of patients' illness stories may help nursing students to get in touch with their innate capacities for empathy. These findings are in agreement with the study of Heidke et $\mathrm{al}^{37}$ which revealed that incorporation of recorded health-care consumers' interviews in a first-year nursing course significantly improved empathy in students. In line with recent studies highlighting the efficacy of experiential learning in empathy-competence acquisition, ${ }^{27,30,46-50}$ our results indicate moderate levels of empathy among nursing students at baseline, which had significantly improved, after intervention, as noted by other similar studies..$^{23,41,46,49-51}$

In the JSE-HPS results of the EG, both the perspectivetaking and compassionate-care subscales presented improvements, unlike the study of Lee et al, ${ }^{49}$ in which the authors reported that patient intervention in nursing training may emphasize self-reflection on what the patient requires and thus cognitive empathy.

Consistently with most studies, ${ }^{3,41,47}$ our sample predominantly consisted of females with higher levels of empathy than males at baseline. In accordance with other studies,${ }^{10,41}$ at baseline our male students presented low empathy values on the BEES, which had significantly increased in both EG and CG among male students after training. These data highlight that in both groups, all educational strategies implemented were effective in sensitizing male students to the importance of empathy in the therapeutic relationship. In light of our results and in accordance with Dinkins, ${ }^{29}$ we suggest that nurse training might be focused on strategies aimed at unblocking innate empathic capacities for improving student awareness of their capacity to understand and support patients.

In contrast to another Italian study, ${ }^{41}$ which highlighted that the training course was effective only in female students, we observed that in the EG both sexes had improved their empathy capacity after training on the BEES score, whereas in the CG only male students showed an increase in empathy, probably because they presented very low levels of empathy at baseline. In this regard, we suggest that since assessment of empathy reached was self-reported, males could have overestimated changes achieved in their empathic capacity.

\section{Limitations of the study}

The results should be read in light of some limits. One of the main ones is conduction of evaluation through two self-reported scales; therefore, we cannot exclude the possibility that the outcomes may have been subject to social desirability bias. The characteristics of the educational intervention did not make blinding of the sample possible. Our study did not investigate the relationship between selfreport measures of empathy and patients' empathy perception. Moreover, this study was conducted only among first-year students, without any follow-up 
evaluation in the same sample to verify long-term effects of educational interventions. In generalizing the findings, we must take into account that the study was monocentric, despite the fact that the sample was correctly sized and that the sex composition reflected Italian nursing students.

\section{Strengths of the study}

Our study, which is one of few randomized controlled trials on the educational effect of patient-experience training, provides evidence for implementing effective educational strategies to increase empathy. Moreover, our research highlighted sex differences in empathy capacity and empathy development during a nursing course.

\section{Conclusion}

Experiential training with expert patient involvement has been shown to be effective in improving empathy levels in both male and female students, indicating that it can be a promising modality of nursing education. In light of our results, we suggest that patients' autonomous and authentic voices and life experiences can support empathic identification with their suffering and understanding of the patient perspective. We conclude by emphasizing that empathic ability can be developed in nursing courses and that patient experiences, stories, and perspectives can help students to be more in touch with their innate capacity for empathy and, therefore, with patient's sufferance.

\section{Ethical approval}

The present study was approved by the local ethics committee of Area Vasta Emilia Nord (protocol 1763 of May $11,2017)$ and was conducted following the principles of the World Medical Association Declaration of Helsinki (1964).

\section{Acknowledgments}

The authors would like to thank all students who participated in this study and the expert patients. We would also like to thank nursing teachers Chiara Cornia, Carmela Giudice, Rosa Miccoli, and Nunzio Panzera. Finally, we thank Orianna Raggioli for her language revision. This work was supported by the Department of Diagnostic, Clinical, and Public Health Medicine, University of Modena and Reggio Emilia (grant 267/2016, protocol 81676, June 28, 2016).

\section{Disclosure}

The authors report no conflicts of interest in this work.

\section{References}

1. Stepien KA, Baernstein A. Educating for empathy. A review. $J$ Gen Intern Med. 2006;21(5):524-530. doi:10.1111/j.1525-1497. 2006.00443.x

2. Derksen F, Bensing J, Lagro-Janssen A. Effectiveness of empathy in general practice: a systematic review. Br J Gen Pract. 2013;63(606): e76-e84. doi:10.3399/bjgp13X660814

3. Brunero S, Lamont S, Coates M. A review of empathy education in nursing. Nurs Inq. 2010;17(1):65-74. doi:10.1111/j.1440-1800. 2009.00482.x

4. Halldorsdottir S. The dynamics of the nurse-patient relationship: introduction of a synthesized theory from the patient's perspective. Scand J Caring Sci. 2008;22(4):643-652. doi:10.1111/j.14716712.2007.00568.x

5. Mercer SW, Higgins M, Bikker AM, et al. General practitioners' empathy and health outcomes: a prospective observational study of consultations in areas of high and low deprivation. Ann Fam Med. 2016;14(2):117-124. doi:10.1370/afm.1910

6. Derksen F, Olde Hartman TC, van Dijk A, Plouvier A, Bensing J, Lagro-Janssen A. Consequences of the presence and absence of empathy during consultations in primary care: a focus group study with patients. Patient Educ Couns. 2017;100(5):987-993. doi:10.1016/j.pec.2016.12.003

7. Cánovas L, Carrascosa AJ, García M, et al. Impact of empathy in the patient-doctor relationship on chronic pain relief and quality of life: a prospective study in Spanish pain clinics. Pain Med. 2018;19 (7):1304-1314. doi:10.1093/pm/pnx160

8. Wang H, Kline JA, Jackson BE, et al. Association between emergency physician self-reported empathy and patient satisfaction. PLoS One. 2018;13(9):e0204113. doi:10.1371/journal.pone.0204113

9. Doyle K, Hungerford C, Cruickshank M. Reviewing tribunal cases and nurse behaviour: putting empathy back into nurse education with Bloom's taxonomy. Nurse Educ Today. 2014;34(7):1069-1073. doi:10.1016/j.nedt.2014.02.004

10. Ferri P, Guerra E, Marcheselli L, Cunico L, Di Lorenzo R. Empathy and burnout: an analytic cross-sectional study among nurses and nursing students. Acta Biomed. 2015;86(2S):104-115.

11. Hemsley B, Sigafoos J, Balandin S, et al. Nursing the patient with severe communication impairment. $J$ Adv Nurs. 2001;35(6):827-835.

12. Ter Beest $H$, van Bemmel $M$, Adriaansen M. Nursing student as patient: experiential learning in a hospital simulation to improve empathy of nursing students. Scand J Caring Sci. 2018;32(4):13901397. doi: $10.1111 / \mathrm{scs} .12584$

13. Jangland E, Gunningberg L, Carlsson M. Patients' and relatives' complaints about encounters and communication in health care: evidence for quality improvement. Patient Educ Couns. 2009;75 (2):199-204. doi:10.1016/j.pec.2008.10.007

14. Williams J, Stickley T. Empathy and nurse education. Nurse Educ Today. 2010;30(8):752-755. doi:10.1016/j.nedt.2010.01.018

15. Kahriman I, Nural N, Arslan U, Topbas M, Can G, Kasim S. The effect of empathy training on the empathic skills of nurses. Iran Red Crescent Med J. 2016;18(6):e24847. doi:10.5812/ircmj

16. Ozcan CT, Oflaz F, Sutcu Cicek H. Empathy: the effects of undergraduate nursing education in Turkey. Int Nurs Rev. 2010;57(4):493499. doi:10.1111/j.1466-7657.2010.00832.x

17. Nunes P, Williams S, Bidyadhar SB, Stevenson K. A study of empathy decline in students from five health disciplines during their first year of training. Int $J$ Med Educ. 2011;2:12-17. doi:10.5116/ ijme.4d47.ddb0 
18. Ward J, Cody J, Schaal M, Hojat M. The empathy enigma: an empirical study of decline in empathy among undergraduate nursing students. J Prof Nurs. 2012;28(1):34-40. doi:10.1016/j.profnurs. 2011.10.007

19. Galán González-Serna JM, Serrano RR, Martín MS, Alarcón Fernández JM. Descenso de empatía en estudiantes de enfermería y análisis de posibles factores implicados. Psicología Educativa. 2014;20:53-60. doi:10.1016/j.pse.2014.05.007

20. Ferri P, Rovesti S, Panzera N, Marcheselli L, Bari A, Di Lorenzo R. Empathic attitudes among nursing students: a preliminary study. Acta Biomed. 2017;88(3S):22-30. doi:10.23750/abm.v88i3-S.6610

21. Ozcan CT, Öksüz E, Oflaz F. Improving empathy in nursing students: a comparative longitudinal study of two curricula. J Korean Acad Nurs. 2018;48(5):497-505. doi:10.4040/jkan.2018.48.5.497

22. Bauchat JR, Seropian M, Jeffries PR. Communication and empathy in the patient-centered care model. Why simulation-based training is not optional. Clin Simul Nurs. 2016;12(8):356-359. doi:10.1016/j. ecns.2016.04.003

23. Gholamzadeh S, Khastavaneh M, Khademian Z, Ghadakpour S. The effects of empathy skills training on nursing students' empathy and attitudes toward elderly people. BMC Med Educ. 2018;18(1):198. doi:10.1186/s12909-018-1297-9

24. Engen HG, Singer T. Empathy circuits. Curr Opin Neurobiol. 2013;23(2):275-282. doi:10.1016/j.conb.2012.11.003

25. Hojat M. Empathy in Patient Care: Antecedents, Development, Measurement, and Outcomes. New York: Springer; 2016.

26. Kiosses VN, Karathanos VT, Tatsioni A. Empathy promoting interventions for health professionals: a systematic review of RCTs. $J$ Compassionate Health Care. 2016;3:7. doi:10.1186/s40639-0160024-9

27. Larti N, Ashouri E, Aarabi A. The effect of an empathy role-play program for operating room nursing students. J Educ Eval Health Prof. 2018;15:29. doi:10.3352/jeehp.2018.15.29

28. Rhodes CA. Service user involvement in preregistration children's nursing education: the impact and influence on practice: a case study on the student perspective. Issues Compr Pediatr Nurs. 2013;36 (4):291-308. doi:10.3109/01460862.2013.830161

29. Dinkins CS. Helping nursing students unblock empathy: a big idea from William James. Nurse Educ Today. 2018;61:194-196. doi:10.1016/j.nedt.2017.11.027

30. Levett-Jones T, Cant R, Lapkin S. A systematic review of the effectiveness of empathy education for undergraduate nursing students. Nurse Educ Today. 2019;75:80-94. doi:10.1016/j.nedt. 2019.01.006

31. Towle A, Bainbridge L, Godolphin W, et al. Active patient involvement in the education of health professionals. Med Educ. 2010;44 (1):64-74. doi:10.1111/j.1365-2923.2009.03530.x

32. Jha V, Quinton ND, Bekker HL, Roberts TE. Strategies and interventions for the involvement of real patients in medical education: a systematic review. Med Educ. 2009;43(1):10-20. doi:10.1111/j.13652923.2008.03244.x

33. Morgan A, Jones D. Perceptions of service user and carer involvement in healthcare education and impact on students' knowledge and practice: a literature review. Med Teach. 2009;31(2):82-95. doi:10.1080/01421590802526946

34. Spencer J, Godolphin W, Karpenko N, Towle A Report: can patients be teachers? Involving patients and service users in healthcare professionals' education. The Health Foundation; 2011. Available from: https://www.health.org.uk/publications/can-patients-be-teachers. Accessed March 11, 2019.
35. Scammell J, Heaslip V, Crowley E. Service user involvement in preregistration general nurse education: a systematic review. J Clin Nurs. 2016;25(1-2):53-69. doi:10.1111/jocn.13068

36. Feijoo-Cid M, Moriña D, Gómez-Ibáñez R, Leyva-Moral JM. Expert patient illness narratives as a teaching methodology: a mixed method study of student nurses satisfaction. Nurse Educ Today. 2017;50:1-7. doi:10.1016/j.nedt.2016.11.029

37. Heidke P, Howie V, Ferdous T. Use of healthcare consumer voices to increase empathy in nursing students. Nurse Educ Pract. 2018;29:3034. doi:10.1016/j.nepr.2017.11.007

38. Regan de Bere S, Nunn S. Towards a pedagogy for patient and public involvement in medical education. Med Educ. 2016;50(1):79-92. doi:10.1111/medu. 12880

39. Towle A, Farrell C, Gaines ME, et al. The patient's voice in health and social care professional education: the Vancouver statement. Int J Health Gov. 2016;21(1):18-25. doi:10.1108/IJHG-01-2016-0003

40. Everson N, Levett-Jones T, Pitt V. The impact of educational interventions on the empathic concern of health professional students: a literature review. Nurse Educ Pract. 2018;31:104-111. doi:10.1016/j. nepr.2018.05.015

41. Cunico L, Sartori R, Marognolli O, Meneghini AM. Developing empathy in nursing students: a cohort longitudinal study. J Clin Nurs. 2012;21(1314):2016-2025. doi:10.1111/j.1365-2702.2012.04105.x

42. Meneghini AM, Sartori R, Cunico L. Italian Adaptation of the Balanced Emotional Empathy Scale (BEES) by A. Mehrabian. Firenze: Giunti Organizzazioni Speciali; 2016.

43. Mehrabian A. Manual for the Balanced Emotional Empathy Scale (BEES). 1130 Alta Mesa Road, Monterey, CA, USA 93940: Albert Mehrabian; 1996.

44. Montanari P, Petrucci C, Russo S, Murray I, Dimonte V, Lancia L. Psychometric properties of the Jefferson scale of empathy-health professional student's version: an Italian validation study with nursing students. Nurs Health Sci. 2015;17(4):483-491. doi:10.1111/nhs.12221

45. Faul F, Erdfelder E, Lang AG, Buchner A. G*Power 3: a flexible statistical power analysis program for the social, behavioral, and biomedical sciences. Behav Res Methods. 2007;39(2):175-191.

46. Chen AM, Kiersma ME, Yehle KS, Plake KS. Impact of the Geriatric Medication Game ${ }^{\circledR}$ on nursing students' empathy and attitudes toward older adults. Nurse Educ Today. 2015;35(1):38-43. doi:10.1016/j.nedt.2014.05.005

47. Bas-Sarmiento P, Fernández-Gutiérrez M, Baena-Baños M, RomeroSánchez JM. Efficacy of empathy training in nursing students: a quasi-experimental study. Nurse Educ Today. 2017;59:59-65. doi:10.1016/j.nedt.2017.08.012

48. Haley B, Heo S, Wright P, Barone C, Rettigantid MR, Anders M. Effects of using an advancing care excellence for seniors simulation scenario on nursing student empathy: a randomized controlled trial. Clin Simul Nurs. 2017;13(10):511-519. doi:10.1016/j.ecns.2017. 06.003

49. Lee KC, Yu CC, Hsieh PL, Li CC, Chao Y. Situated teaching improves empathy learning of the students in a BSN program: a quasi-experimental study. Nurse Educ Today. 2018;64:138-143. doi:10.1016/j.nedt.2018.02.013

50. Yang N, Xiao H, Cao Y, Li S, Yan H, Wang Y. Does narrative medicine education improve nursing students' empathic abilities and academic achievement? A randomised controlled trial. J Int Med Res. 2018;46(8):3306-3317. doi:10.1177/0300060518781476

51. Chen PJ, Huang CD, Yeh SJ. Impact of a narrative medicine programme on healthcare providers' empathy scores over time. BMC Med Educ. 2017;17(1):108. doi:10.1186/s12909-017-0929-9 


\section{Publish your work in this journal}

Psychology Research and Behavior Management is an international, peer-reviewed, open access journal focusing on the science of psychology and its application in behavior management to develop improved outcomes in the clinical, educational, sports and business arenas. Specific topics covered in the journal include: Neuroscience, memory and decision making; Behavior modification and management; Clinical applications; Business and sports performance management; Social and developmental studies; Animal studies. The manuscript management system is completely online and includes a very quick and fair peer-review system, which is all easy to use. Visit http://www. dovepress.com/testimonials.php to read real quotes from published authors.

Submit your manuscript here: https://www.dovepress.com/psychology-research-and-behavior-management-journal 